\begin{tabular}{|c|l|}
\hline Title & $\begin{array}{l}\text { Role of platinum deposits on titanium(IV) oxide particles: structural and kinetic analyses of photocatalytic reaction in } \\
\text { aqueous alcohol and amino acid solutions }\end{array}$ \\
\hline Author(s) & Ohtani, Bunsho; Iwai, Kunihiro; Nishimoto, Seiichi; Sato, Shinri \\
\hline Citation & $\begin{array}{l}\text { Journal of physical chemistry. B, 101(17), 3349-3359 } \\
\text { https://doi.org/10.1021/p962060q }\end{array}$ \\
\hline Issue Date & 1997-0424 \\
\hline Doc URL & http://hdl.handle.net/2115/52792 \\
\hline Type & article \\
\hline File Information & jp962060q.pdf \\
\hline
\end{tabular}

Instructions for use 


\title{
Role of Platinum Deposits on Titanium(IV) Oxide Particles: Structural and Kinetic Analyses of Photocatalytic Reaction in Aqueous Alcohol and Amino Acid Solutions
}

\author{
Bunsho Ohtani, ${ }^{*},+\ddagger$ Kunihiro Iwai, ${ }^{\dagger}$ Sei-ichi Nishimoto, ${ }^{\dagger}$ and Shinri Sato ${ }^{\S}$ \\ Contribution from the Department of Energy and Hydrocarbon Chemistry, Graduate School of Engineering, \\ Kyoto University, Kyoto 606-01, Japan, and Catalysis Research Center, Hokkaido University, \\ Sapporo 060, Japan
}

Received: July 10, 1996; In Final Form: December 4, $1996^{\otimes}$

\begin{abstract}
Photocatalytic reaction at $298 \mathrm{~K}$ by platinum-loaded titanium(IV) oxide $\left(\mathrm{TiO}_{2}-\mathrm{Pt}\right)$ particles suspended in deaerated aqueous solutions of 2-propanol or $\left(S\right.$ )-lysine (Lys) was investigated. The $\mathrm{TiO}_{2}$ catalysts with various amounts of $\mathrm{Pt}$ loadings were prepared by impregnation from aqueous chloroplatinic acid solution onto a commercial $\mathrm{TiO}_{2}$ (Degussa P-25) followed by hydrogen reduction at $753 \mathrm{~K}$. The physical properties of deposited Pt, e.g., particle size, surface area, and electronic state, were studied respectively by transmission electron microscopy, volumetric gas adsorption measurement, and X-ray photoelectron spectroscopy as well as infrared spectroscopy of adsorbed carbon monoxide. The increase in Pt amount mainly resulted in an increase of the number of Pt deposits, not of their size. The catalysts were suspended in the aqueous solutions and photoirradiated at a wavelength $>300 \mathrm{~nm}$ under an argon (Ar) atmosphere. The overall rate of photocatalytic reactions for both 2-propanol and Lys, corresponding to the rate of consumption of these substrates, was negligible without Pt loading, increased drastically with the loading up to ca. $0.3 \%$, and was almost constant or a little decreased by the further loadings. However, the rate of formation of pipecolinic acid (PCA) from Lys was improved gradually with a increase of Pt loading up to ca. $2 \mathrm{wt} \%$. These dependences were discussed as a function of Pt surface area, which is employed as a measure that includes the properties of both number and size of Pt deposits. For the photocatalytic dehydrogenation of 2-propanol, the rate dependence could be interpreted semiquantitatively with the model that only the $\mathrm{TiO}_{2}$ particles loaded with at least one Pt deposit can photocatalyze, but the reaction rate is independent of the number of Pt deposits. Therefore, the overall rate is proportional to the number of $\mathrm{Pt}$-loaded $\mathrm{TiO}_{2}$ particles. On the other hand, for the interpretation of the rate of $\mathrm{PCA}$ and $\mathrm{H}_{2}$ productions, the number of Pt deposits on each $\mathrm{TiO}_{2}$ particle had to be taken into account. The efficient production of PCA at higher Pt loadings was attributed to the reduction of a Schiff base intermediate produced via oxidation of Lys with positive holes and subsequent intramolecular condensation at the Pt deposit that is close to the site for the oxidation. Otherwise, photoexcited electrons are consumed for $\mathrm{H}_{2}$ production and the intermediate remains unreduced or undergoes further oxidation. It was suggested that the intermediate produced at the $\mathrm{TiO}_{2}$ surface sites within a distance of several nanometers from the Pt deposit undergoes efficient reduction to PCA. Thus, the importance of the distribution of $\mathrm{Pt}$ deposits for the preparation of highly active and selective $\mathrm{TiO}_{2}-\mathrm{Pt}$ photocatalyst has been clearly demonstrated.
\end{abstract}

\section{Introduction}

Semiconductor photocatalytic reaction is initiated by oxidation and reduction respectively with positive holes $\left(\mathrm{h}^{+}\right)$and photoexcited electrons $\left(\mathrm{e}^{-}\right)$both of which are produced by photoabsorption of semiconducting materials. ${ }^{1,2}$ Separation of these charges can be expected when the semiconducting materials are in contact with the electrolyte solution. Formation of the space charge layer at, for example, the n-type semiconductor-solution interface may promote transfer of $\mathrm{h}^{+}$to the surface and $\mathrm{e}^{-}$to the inner space, resulting in the efficient utilization of these charges in chemical reaction with lesser mutual recombination. ${ }^{3}$ Among the reactions occurring at the interface, photoinduced splitting of water into hydrogen $\left(\mathrm{H}_{2}\right)$ and oxygen $\left(\mathrm{O}_{2}\right)$ has been one of the most significant targets of the semiconductor photocatalysis, since the system can be applied to conversion of solar energy into chemical energy. ${ }^{3}$ Although titanium(IV) oxide $\left(\mathrm{TiO}_{2}\right)$ can absorb only the ultraviolet region (less than

\footnotetext{
$\dagger$ Kyoto University.

$¥$ Present address: Division of Chemistry, Graduate School of Science, Hokkaido University, Sapporo 060, Japan.

$\S$ Hokkaido University.

${ }^{\otimes}$ Abstract published in Advance ACS Abstracts, April 1, 1997.
}

ca. $400 \mathrm{~nm}$ ) of the whole solar radiation, it has been used and investigated widely because of its high photostability and relatively high activity. Several reaction systems employing the $\mathrm{TiO}_{2}$ photocatalysts have achieved water-splitting without gradual loss of $\mathrm{TiO}_{2}$ catalytic activity. ${ }^{4-12}$ These successful results could be obtained by loading small amounts of pltinum (Pt) and/or ruthenium(IV) oxide $\left(\mathrm{RuO}_{2}\right)$ onto the $\mathrm{TiO}_{2}$ particles. The noble metal (or its oxide) deposits have been interpreted to act as a catalyst for the $\mathrm{H}_{2}$ evolution by $\mathrm{e}^{-}$, i.e., they reduce the activation energy for water reduction. Isotope distribution studies for the photocatalytic splitting of water have proved the catalytic effect of Pt deposits. ${ }^{13,14}$ Kraeutler and Bard have reported the photocatalytic preparation of $\mathrm{TiO}_{2}-\mathrm{Pt}$ from aqueous solution of chloroplatinic acid $\left(\mathrm{H}_{2} \mathrm{PtCl}_{6}\right)$ and used for decarboxylation of acetic acid, the photo-Kolbe reaction, producing methane and carbon dioxide under deaerated conditions. ${ }^{15,16} \mathrm{By}$ using platinized $\mathrm{TiO}_{2}$ photocatalysts in the absence of $\mathrm{O}_{2}$, generally, hydrogen evolution proceeds as a counter reaction of oxidation by $\mathrm{h}^{+}$, e.g., primary and secondary alcohols are converted into aldehydes and ketones with the evolution of equimolar amount of $\mathrm{H}_{2} \cdot{ }^{17-25} \mathrm{Pt}$ loading also gives a decisive effect for these reactions; a significant amount of the products 
was seen only when $\mathrm{Pt}$ was loaded effectively. Thus, an extensive number of reactions by $\mathrm{TiO}_{2}-\mathrm{Pt}$ under deaerated conditions have been reported so far, ${ }^{26}$ but the limited number of investigations showed the mechanism and the relation between properties of $\mathrm{Pt}$ deposits and photocatalytic activities. A unique report, to the best of our knowledge, by Pichat and co-workers ${ }^{27}$ described the photocatalytic activity of a series of $\mathrm{TiO}_{2}-\mathrm{Pt}$ photocatalysts and discussed the correlation with their physical properties.

As an application of semiconductor photocatalysis, we have reported photocatalytic organic syntheses ${ }^{28}$ especially use of amino acid analogues as a starting material. For example, ${ }^{29-31}$ a natural amino acid, $(S)$-lysine (Lys), undergoes photocatalytic deamino- $N$-cyclization into $(S)$-pipecolinic acid (PCA), a naturally occurring but nonproteinogenic amino acid, under deaerated conditions. These series of $N$-cyclization ${ }^{32}$ and $N$-alkylation $^{33,34}$ or amines, in contrast to the other photocatalytic reactions such as water splitting or dehydrogenation of alcohols described above, proceed via the combination of oxidation with $\mathrm{h}^{+}$and reduction with $\mathrm{e}^{-}$. The amines are first oxidized by $\mathrm{h}^{+}$ into the corresponding imines, hydrolyzed to aldehyde, and then condensed with another molecule of the amine to form a Schiff base intermediate undergoing reduction by $\mathrm{e}^{-}$(see Scheme 1). The combination of oxidation and reduction affords, in principle, no byproducts and needs no electrolytes as used in electrolyses, since both reactions occur in the neighborhood of the particle surface. For the photocatalytic $N$-cyclization of Lys, the $\mathrm{Pt}$ loading is also indispensable; apparently, no consumption of Lys and production of PCA could be seen with bare $\mathrm{TiO}_{2}$ powders. ${ }^{29}$ Similar to the $\mathrm{H}_{2}$ evolution systems, $\mathrm{Pt}$ may act as a reduction site in this case also. For a better understanding of the reaction mechanism and role of the Pt deposit, as well as successful preparation of the semiconductor photocatalyst for the PCA synthesis, clarification of the correlation between the physical properties of $\mathrm{Pt}$ and photocatalytic activity (or product selectivity) is required.

In a series of kinetic studies for photocatalytic reactions, we have demonstrated that a simple kinetic model can reproduce the dependences of reaction rate on, for example, concentrations of reaction substrates. Linear relations of reaction rates of silver metal deposition ${ }^{35,36}$ or acetone production ${ }^{37}$ with the amount of adsorbed silver cation $\left(\mathrm{Ag}^{+}\right)$or 2-propanol from aqueous suspension of $\mathrm{TiO}_{2}$ have been interpreted with the model, including reductive and oxidative trappings of excited electronpositive hole pair $\left(\mathrm{e}^{-}-\mathrm{h}^{+}\right)$with surface-adsorbed $\mathrm{Ag}^{+}$and 2-propanol, respectively. This kinetic model was also applicable to the photocatalytic reaction system in which both reductive and oxidative trappings are presumed. ${ }^{38}$ It has been suggested that actual photocatalytic reaction rates are interpreted without considering the effect of charge separation in the space-charge layer at solution-semiconductor interface, i.e., the spontaneous charge separation is not a requisite for the explanation of kinetic data for the case where strong oxidant and/or reductant is present (however, in the case of an uphill reaction, e.g., water splitting, certain charge separation mechanisms must be present, since the efficiency has been shown to be high enough ${ }^{9,39}$ ). Our purpose is to extend the kinetic model to the photocatalytic reaction system with platinized $\mathrm{TiO}_{2}$ particles and to clarify the role of $\mathrm{Pt}$ deposits. In this study, a series of $\mathrm{TiO}_{2}-\mathrm{Pt}$ photocatalysts with varying Pt amounts were prepared and used for the photocatalytic reaction of 2-propanol dehydrogenation and conversion of Lys into PCA. Their rates were compared and analyzed as a function of physical property of Pt. The different dependences could be interpreted by considering the distribution of Pt deposits.

\section{Experimental Section}

Materials. Commercial $\mathrm{TiO}_{2}$ (Degussa P-25) was used throughout this study as one of the most active $\mathrm{TiO}_{2}$ photocatalysts. ${ }^{31,40}$ Loading of $\mathrm{Pt}$ onto the $\mathrm{TiO}_{2}$ powder was accomplished by impregnation and subsequent $\mathrm{H}_{2}$ reduction at elevated temperature, ${ }^{41,42}$ following the method reported by Pichat and co-workers. ${ }^{17}$ To an aqueous suspension $\left(300 \mathrm{~cm}^{3}\right)$ of $\mathrm{TiO}_{2}$ (ca. $5 \mathrm{~g}$ ), an aqueous solution of chloroplatinic acid $\left(\mathrm{H}_{2} \mathrm{PtCl}_{6} \cdot 6 \mathrm{H}_{2} \mathrm{O}\right.$, in most cases ca. $\left.1 \mathrm{mmol} \mathrm{dm}^{-3}\right)$ was added dropwise for $1 \mathrm{~h}$ under magnetic stirring at room temperature. The mixture was gently stirred for additional $2 \mathrm{~h}$, evaporated to dryness at $323 \mathrm{~K}$, and then further dried at $383 \mathrm{~K}$ for $12 \mathrm{~h}$ in an oven. The off-white (or slightly yellow, depending on the amount of loaded $\mathrm{Pt}$ ) powder thus obtained was ground in an agate mortar and placed in a Pyrex cylindrical vessel. The vessel was heated in an electric furnace to $753 \mathrm{~K}$ at a rate of ca. $20 \mathrm{~K} \mathrm{~min}^{-1}$ under a gas stream $\left(35 \mathrm{~cm}^{3} \mathrm{~min}^{-1}\right)$, kept at that temperature for $3 \mathrm{~h}$, and then allowed to cool to ambient temperature. Argon (Ar) up to an elevating temperature of 573 $\mathrm{K}$ and $\mathrm{H}_{2}$ were made to flow through a Pyrex tube inserted in the vessel. Mass-flow controllers were used for the adjustment of gas flow during the treatment. The vessel was inclined and turned at ca. $70 \mathrm{rpm}$ throughout the reduction process to avoid heterogeneity. The photocatalyst powders were kept in air at room temperature.

Transmission Electron Microscopy. The size and number of $\mathrm{Pt}$ deposits loaded on $\mathrm{TiO}_{2}$ were determined by transmission electron microscopy (TEM). A few milligrams of finely ground catalyst was mixed with a few drops of 2-propanol and brayed between two slide glass plates to form a uniform suspension. The glass plates with the suspension were carefully inserted into distilled water to float small agglomerates of catalyst on the surface of water. They were collected on a copper microgrid covered with collodion and carbon (Oken, type B) and dried in air. The thus-obtained sample was observed with a transmission electron microscope, Hitachi $\mathrm{H}-800$, operated at $175 \mathrm{kV}$ of electron acceleration voltage. ${ }^{30}$ The micrographs were recorded with magnification between 100000 and 400000 .

Volumetric Gas Adsorption. The surface area of loaded Pt was evaluated by volumetric gas adsorption measurements, which is based on the selective chemisorption of $\mathrm{H}_{2}$ onto the surface of noble metals. ${ }^{43-45}$ The measurements were performed with a glass vacuum line equipped with an oil diffusion pump, capacitance manometers (MKS Baratron type 122A), and Pyrex sample vessels. Pretreatment of the sample (ranging 100-600 mg, depending on the surface area of Pt) was based on the reported procedure ${ }^{43}$ with a little modification as follows. The catalyst powder was evacuated $\left(1.33 \mathrm{mPa}=1 \times 10^{-5}\right.$ Torr $)$ and heated at $473 \mathrm{~K}$ for $1 \mathrm{~h}$ in an electric furnace followed by cooling to room temperature. The sample vessel was then kept at $473 \mathrm{~K}$ for $1 \mathrm{~h}$ under $\mathrm{H}_{2}$ (initial pressure was $13.3 \mathrm{kPa}=100$ Torr) and evacuated at room temperature for $10 \mathrm{~min}$ to obtain a clean surface. After this pretreatment, $\mathrm{H}_{2}$ was introduced in the sample vessel and equilibrated for at least $20 \mathrm{~min}$. The measurements were made at several equilibrium pressures of $\mathrm{H}_{2}$ up to ca. $5 \mathrm{kPa}$.

X-Ray Photoelectron Spectroscopy. X-ray photoelectron spectroscopic (XPS) measurements were carried out with a ULVAC PHI 5500 Multi Technique system with a dual anode $\mathrm{X}$-ray source $(\mathrm{Mg} \mathrm{K} \alpha 15 \mathrm{kV}, 400 \mathrm{~W})$. The pass energy of the hemispherical capacitor analyzer was $29.350 \mathrm{eV}$. The photocatalyst powder was pressed in a die (ca. $1000 \mathrm{~kg}$ ) into a selfsupporting disk of $2 \mathrm{~cm}$ diameter and introduced in the instrument. The angle between the sample surface and electron beam was $45^{\circ}$. During the measurements, the analyzer chamber 

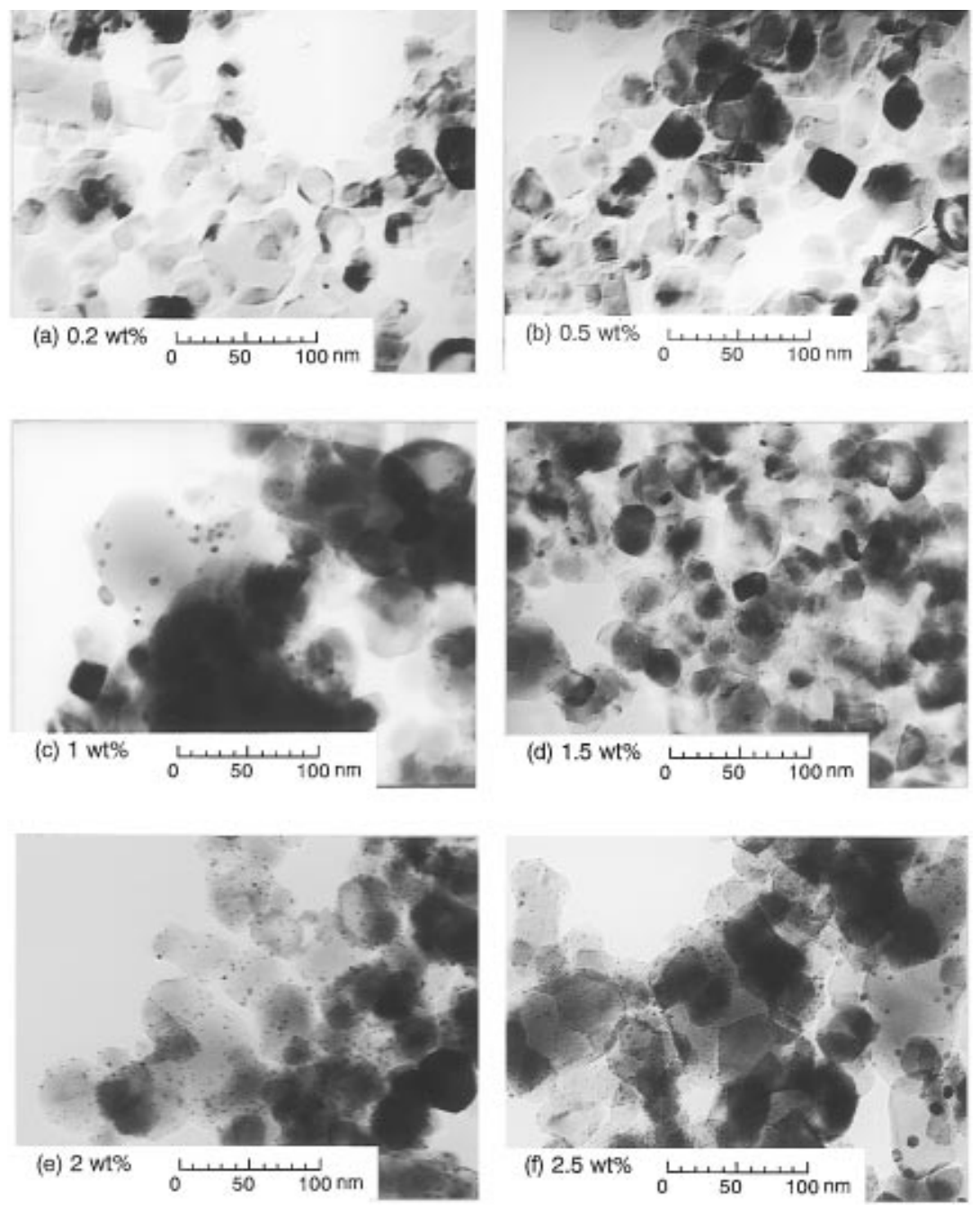

Figure 1. Transmission electron micrographs of $\mathrm{TiO}_{2}$ loaded with various amounts of Pt: (a) 0.2 , (b) 0.5 , (c) 1 , (d) 1.5 , (e) 2 , and (f) 2.5 wt $\%$ of Pt.

was ketp at a pressure less than $133 \mathrm{nPa}\left(=10^{-9}\right.$ Torr $)$. Spectra in $\mathrm{C} 1 \mathrm{~s}$, Ti 2p, $\mathrm{O} 1 \mathrm{~s}$, and $\mathrm{Pt} 4 \mathrm{f}$ regions were recorded, and all the binding energy was corrected with reference to a contained C 1s core line $(284.6 \mathrm{eV})$.

Infrared Spectroscopy. A $\mathrm{TiO}_{2}$ sample (ca. $70 \mathrm{mg}$ ) was pressed in a die $(12 \mathrm{~mm}$ in diameter, $5000 \mathrm{~kg}$ ) into a self-supporting pellet. The pellet was set in a Pyrex cell equipped with calcium fluoride windows for infrared (IR) measurements and with a heater for degassing at higher temperature. ${ }^{46}$ The cell was evacuated $(<133 \mathrm{mPa})$, and the pellet was heated at $523 \mathrm{~K}$ for $1 \mathrm{~h}$. After it was cooled, carbon monoxide (CO) gas (Takachiho) was introduced (ca. $1.33 \mathrm{kPa}$ ) and equilibrated for ca. $15 \mathrm{~min}$ at ambient temperature. The IR measurement was performed with a Perkin-Elmer 1720X FT-IR spectrometer in transmission mode. The resolution was $4 \mathrm{~cm}^{-1}$ and spectra were recorded by accumulation of 100 scans. IR absorption by $\mathrm{CO}$ remaining in the gas phase was negligible, and therefore, spectra of adsorbed $\mathrm{CO}$ was obtained by subtraction of spectra after and before the introduction of CO.

Photoirradiation and Product Analyses. Bare and platinized $\mathrm{TiO}_{2}$ catalyst $(50 \mathrm{mg})$ was suspended in an aqueous solution containing 2-propanol $(500 \mu \mathrm{mol})$ or Lys $(100 \mu \mathrm{mol})$ and photoirradiated under Ar with magnetic stirring (1000 rpm). The temperature of the suspension was kept at $298 \pm 0.5 \mathrm{~K}$ in a thermostated water bath. Irradiation with light of wavelength at $>300 \mathrm{~nm}$ from a high-pressure mercury arc (Eiko-sha 400) was performed through a cylindrical Pyrex glass filter and a reaction vessel. Gaseous products, such as $\mathrm{H}_{2}$ and carbon dioxide $\left(\mathrm{CO}_{2}\right)$, were analyzed by gas chromatography (GC) and liquid-phase product by high-performance liquid chromatography (HPLC). The details of the procedures for photocatalytic reaction and product analyses (for 2-propanol ${ }^{23,47,48}$ and Lys $29,49,50$ systems) were described previously. Note that measurement of small Lys consumption includes relatively large error, since it could be evaluated only by subtraction of the remaining amount of Lys from that in feed. The measurement of ammonia $\left(\mathrm{NH}_{3}\right)$ was also accompanied by larger errors because of the interference by contaminated peaks in HPLC analyses and because of its volatility.

\section{Results and Discussion}

Particle Size of Pt Deposits. Figure 1 is representative micrographs of the platinized $\mathrm{TiO}_{2}$ particles. Pt particles were identified as black dots of a few nanometers because of their higher electron density, while $\mathrm{TiO}_{2}$ particles of $20-60 \mathrm{~nm}$ in diameter were observed as grayish grains. For these samples, a uniform distribution of the small Pt deposits could be observed; several deposits were located on the surface of each $\mathrm{TiO}_{2}$ particle. The well-dispersed Pt deposits could be seen in almost all TEM observation fields and for all the Pt-loaded samples. As a general tendency, the number of Pt deposits, but not their size, increased with an increase in the amount of loaded Pt. This is consistent with the previous report by Pichat and coworkers who demonstrated this clearly by TEM pictures. ${ }^{27}$ 

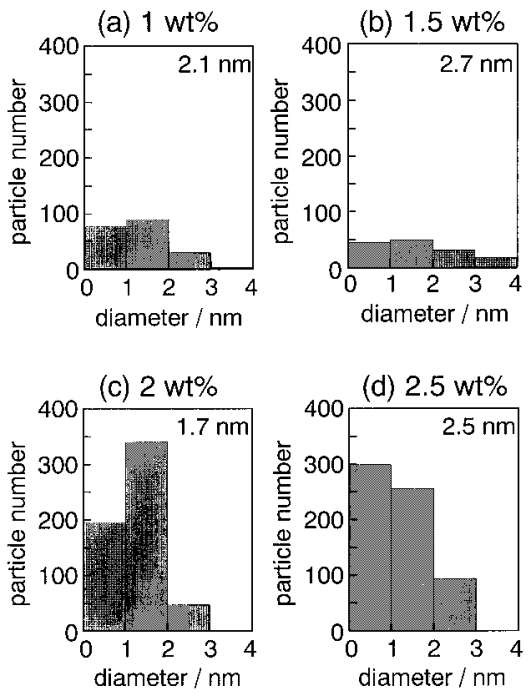

Figure 2. Distribution of size of $\mathrm{Pt}$ deposits where particle numbers were normalized to same amount of $\mathrm{TiO}_{2}$ : (a) 1, (b) 1.5, (c) 2, and (d) $2.5 \mathrm{wt} \%$ of Pt. The number in each square shows the volume-weighted average diameter $\left(d_{\mathrm{ave}}\right)$.

Figure 2 shows the size-distribution of Pt deposits of part of the samples. For this analysis, the Pt deposits on more than $200 \mathrm{TiO}_{2}$ particles of each sample were counted on the assumptions that the $\mathrm{TiO}_{2}$ particles are thin enough to transmit the electron beam of TEM, and thereby the deposits located on the back-side of $\mathrm{TiO}_{2}$ can be seen in the pictures, and that there are no Pt deposits smaller than the limit of discrimination $(<0.3$ $\mathrm{nm})$. Although the distribution pattern was somewhat different from each other, it was commonly observed that almost all Pt deposits were smaller than or equal to $3 \mathrm{~nm}$ and that a maximum distribution was seen in the range $1-2 \mathrm{~nm}$. Actually, volumeweighted average diameter $\left(d_{\text {ave }}\right)$ obtained from the equation

$$
d_{\mathrm{ave}}=\sum N_{i} d_{i}^{3} /\left(\sum N_{i} d_{i}^{2}\right)
$$

where $N_{i}$ is the number of particles of diameter $d_{i}(0.5,1.5$, 2.5 , and $3.5 \mathrm{~nm}$ ), was ca. $2 \mathrm{~nm}$ regardless of Pt amount, as depicted in Figure 2. These distribution patterns may especially depend on the preparation conditions of the thermal decomposition under elevating temperature and hydrogen reduction; e.g., it has been seen that even a small change in the flow rate of $\mathrm{H}_{2}$ during the treatment drastically affects the size distribution. ${ }^{51}$ In the present study, the procedure of catalyst preparation was unchanged, but undetected fluctuation of parameter(s) may produce such a difference in size distribution.

The above-mentioned tendency that the number of Pt deposits changes with total $\mathrm{Pt}$ amount allows us to expect that some $\mathrm{TiO}_{2}$ particles are loaded while the rest remain unloaded. In fact, the unloaded $\mathrm{TiO}_{2}$ particles were found in TEM observation for samples with lower $(<0.2 \mathrm{wt} \%)$ Pt loading. Since it is rather difficult to count the unloaded $\mathrm{TiO}_{2}$ particles from the TEM picture, the proportion $(P(n))$ of $\mathrm{TiO}_{2}$ particles with different number $(n)$ of $\mathrm{Pt}$ deposits was estimated, for convenience, by assuming a Poisson distribution: ${ }^{52}$

$$
P(n)=\langle n\rangle^{n} \exp (-\langle n\rangle) / n ! \quad(n=0,1,2, \ldots)
$$

where $\langle n\rangle$ is the average number of $\mathrm{Pt}$ deposits on a $\mathrm{TiO}_{2}$ particle and is evaluated with the approximation of spherical Pt particles with an above-average particle diameter and with a density of $21.4 \mathrm{~g} \mathrm{~cm}^{-3}$ and $\mathrm{TiO}_{2}$ with $40 \mathrm{~nm}$ and $4.93 \mathrm{~g} \mathrm{~cm}^{-3}$. Some of the results are shown in Figure 3. A large number of $\mathrm{TiO}_{2}$ particles are unloaded with lower Pt loading. As Figure $3 \mathrm{c}$
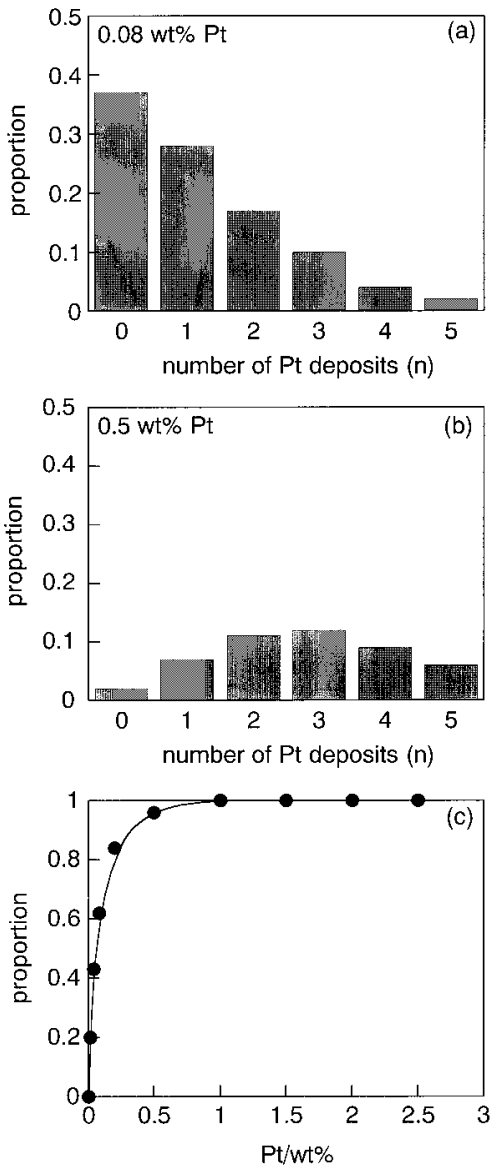

Figure 3. Estimated proportion $P(n)$ of $\mathrm{TiO}_{2}$ particles with different number $n$ of loaded Pt deposits for (a) 0.08 and (b) 0.5 wt \% of Pt. Part c shows the proportion of $\mathrm{TiO}_{2}$ particles loaded with at least one Pt deposit $(1-P(0))$.

shows, the proportion of Pt-loaded $\mathrm{TiO}_{2}(n>0)$ increases with the increase in Pt amount up to ca. $0.5 \mathrm{wt} \%$ and to almost 1 thereafter. This behavior may be closely related to the photocatalytic activity as described later.

Surface Areas of Pt. Volumetric Gas Adsorption Measurements. Figure $4 \mathrm{a}$ shows the typical isotherms of $\mathrm{H}_{2}$ adsorption. Although no $\mathrm{H}_{2}$ adsorption was observed for bare $\mathrm{TiO}_{2}$, Pt-loaded samples adsorbed $\mathrm{H}_{2}$ in appreciable amounts, indicating the adsorption is attributable to Pt deposits. As described in the Experimental Section, the amount of adsorbed $\mathrm{H}_{2}$ was evaluated after heat treatment (at $473 \mathrm{~K}$ ) under $\mathrm{H}_{2}$ atmosphere followed by evacuation at room temperature. Therefore, the adsorption was almost reversible; evacuation at room temperature and reintroduction of $\mathrm{H}_{2}$ led to almost same amount of adsorption. As clearly recognized from the fact that pre-evacuation at a higher temperature, e.g., at $723 \mathrm{~K}$, gave a larger adsorption, it is necessary to define the pretreatment conditions for such an adsorption measurement as discussed later.

For each isotherm, a small but appreciable increase could be obtained, indicating the deviation from Langmuirian adsorption behavior in which adsorption should be saturated at higher equilibrium pressure. This is attributable to spillover the hydrogen atom from $\mathrm{Pt}$ deposits to $\mathrm{TiO}_{2} ;{ }^{14}$ dissociatively adsorbed hydrogen travels to the neighboring $\mathrm{TiO}_{2}$ surface at higher equilibrium pressure. Because the spillover can be neglected at lower pressure, the amount of $\mathrm{H}_{2}$ adsorption on the Pt surface was evaluated by linear extrapolation of the isotherm to zero pressure ${ }^{43,44}$ and converted into the surface area of Pt. A 1:1 adsorption of the hydrogen atom to the surface- 

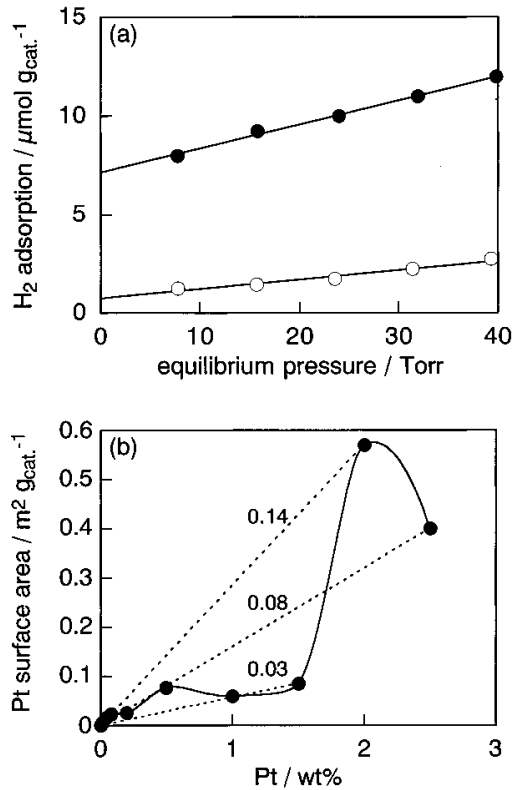

Figure 4. (a) Typical isotherms of $\mathrm{H}_{2}$ adsorption on $1 \mathrm{wt} \%(\mathrm{O})$ and 2 wt $\%(\bullet)$ Pt-loaded $\mathrm{TiO}_{2}(1$ Torr $=133.322 \mathrm{~Pa})$. (b) Surface area of $\mathrm{Pt}$ as a function of its amount. Numbers denote the dispersion of $\mathrm{Pt}$ (see text).

exposed $\mathrm{Pt}$ atom and the exposed area of $\mathrm{Pt}$ atom of $6.66 \times$ $10^{-20} \mathrm{~m}^{2}$ atom ${ }^{-1}$ were assumed for the conversion, in which the latter was estimated from the surface density of $\mathrm{Pt}$ in its (111) crystallographic plane. Figure 4b shows the results, as well as the proportion of $\mathrm{Pt}$ atom exposed to the surface evaluated by assuming that an $\mathrm{H}$ atom is adsorbed on a Pt atom, which is often called "dispersion". Among the samples in this study, the highest proportion (0.14) was obtained for a 2 wt \% loaded sample, but it was rather smaller than the reported value for a loaded Pt catalyst with similar preparation conditions. ${ }^{43,45}$ This may be due to the method of measurement employed in this study; we measured the reversible adsorption but not "total adsorption".

As clearly seen in Figure 4b, the Pt surface area was not proportional to the amount of loaded $\mathrm{Pt}$, reflecting the small difference in size distribution (see Figures 1 and 2). In considering the effect of Pt deposits on the photocatalytic reaction, but the size and the number of the deposits should be taken in account. The Pt surface area corresponds to the part of exposed $\mathrm{Pt}$ atoms and may be an adequate measure of $\mathrm{Pt}$ dispersion, which includes both the parameters as discussed later.

Electronic State of Deposited Pt. XPS and IR Measurements. Figure 5 shows the part of the XPS spectra of the Ptloaded $\mathrm{TiO}_{2}$ in the region of $\mathrm{Pt} 4 \mathrm{f}$. No appreciable difference could be obtained for the other elements, titanium and oxygen. Although the amount of loaded Pt was not enough (2.5 wt \% at most) to give highly resolved spectra, two specific peaks with binding energy of ca. 70 and $74 \mathrm{eV}$ were observed as $4 \mathrm{f}_{7 / 2}$ and $4 \mathrm{f}_{5 / 2}$ electrons of the $\mathrm{Pt}$ metal $\left(\mathrm{Pt}^{0}\right)$, respectively. These peaks were commonly observed for all the Pt samples, suggesting that the $\mathrm{H}_{2}$ treatment step in the catalyst preparation procedure effectively reduces the $\mathrm{Pt}$ source as in the electronic state of $\mathrm{Pt}^{4+}\left(\mathrm{H}_{2} \mathrm{PtCl}_{6}\right.$ or thermally decomposed form of $\left.\mathrm{PtO}_{2}\right)$ to $\mathrm{Pt}^{0}$.

A characteristic phenomenon was seen for the catalyst loaded at 0.5 and 2 wt $\%$ of $\mathrm{Pt}$; shoulders appeared with binding energy higher than those of the two peaks of $\mathrm{Pt}^{0}$, suggesting the presence of a positively charged form of $\mathrm{Pt}$. On the assumption that the ratio of the peak area of $4 f_{7 / 2}$ and $4 f_{5 / 2}$ is constant (1.33) for each platinum species, ${ }^{53}$ the apparent spectra could be deconvoluted into three sets of peaks as shown Figure 5 with
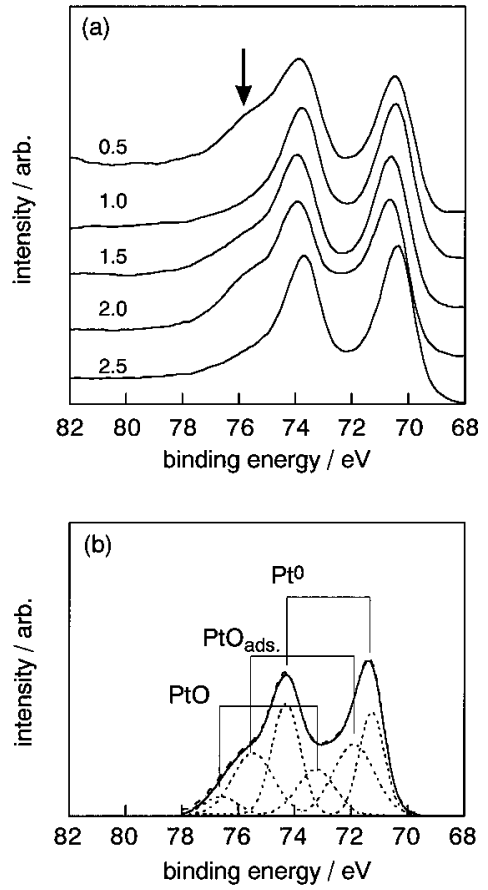

Figure 5. XPS spectra of Pt-loaded with various amount of Pt; (b) deconvoluted spectra of $2 \mathrm{wt} \% \mathrm{Pt}$-loaded $\mathrm{TiO}_{2}$. Dotted line show three sets of peaks. Dashed and solid lines refer to the sum of the deconvoluted spectra and observed spectrum, respectively.

TABLE 1: Results of XPS Analyses of Deposited Pt on $\mathrm{TiO}_{2}$ Particles $^{a}$

\begin{tabular}{lccccc}
\hline & \multicolumn{2}{c}{ peak position/eV } & & \multicolumn{2}{c}{ full width at half maximum/eV } \\
\cline { 2 - 3 } \cline { 5 - 6 } state & $4 \mathrm{f}_{7 / 2}$ & $4 \mathrm{f}_{5 / 2}$ & & $4 \mathrm{f}_{7 / 2}$ & $4 \mathrm{f}_{5 / 2}$ \\
\hline $\mathrm{Pt}$ & $70.5(70.7)$ & $73.9(74.0)$ & & $1.4(1.2)$ & 1.5 \\
$\mathrm{PtO}_{\text {ads }}$ & $71.8(71.8)$ & $75.2(75.1)$ & & $1.9(1.9)$ & 1.8 \\
$\mathrm{PtO}$ & $73.3(73.4)$ & $76.4(76.6)$ & & $1.7(1.3)$ & 1.5
\end{tabular}

${ }^{a}$ Values in parentheses show previous results reported by Kim and co-workers. ${ }^{53}$

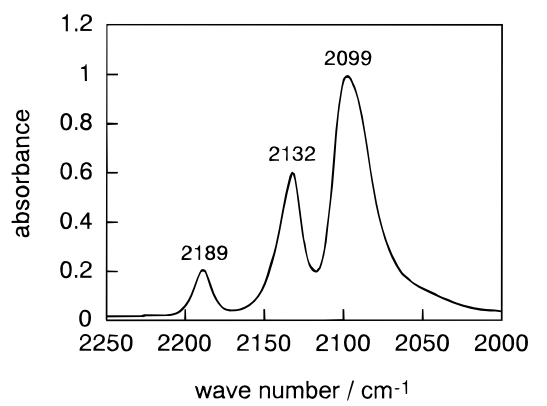

Figure 6. Part of FT-IR spectrum of $\mathrm{CO}$ adsorbed on $\mathrm{TiO}_{2}$ loaded with 2 wt $\%$ of Pt.

the parameters listed in Table 1. They were assigned to $\mathrm{Pt}^{0}, \mathrm{Pt}$ with adsorbed oxygen $\left(\mathrm{PtO}_{\mathrm{ads}}\right)$, and oxidized $\mathrm{Pt}(\mathrm{PtO})$. The last two oxidized forms of Pt could be seen notably for the catalyst with highly dispersed Pt, e.g., 0.5 or 2 wt $\%$ loaded $\mathrm{TiO}_{2}-\mathrm{Pt}$, as shown in Figure 4.

FT-IR spectroscopy of $\mathrm{CO}$ adsorbed on $\mathrm{TiO}_{2}-\mathrm{Pt}$ also supports this phenomenon. As Figure 6 shows, two sharp peaks and one broadened peaks were seen in the $\mathrm{CO}$ stretching region for the highly dispersed Pt sample (2 wt \%). The higher wavenumber peak $\left(2189 \mathrm{~cm}^{-1}\right)$ was commonly observed regardless of the Pt amount and assigned to $\mathrm{CO}$ adsorbed weakly on the $\mathrm{TiO}_{2}$ surface. ${ }^{54,55}$ The lower wavenumber peak (2099 $\left.\mathrm{cm}^{-1}\right)$ may consist mainly of $\mathrm{CO}$ adsorbed on metallic $\mathrm{Pt}\left(\mathrm{Pt}^{0}\right)$ and be also observed for Pt-loaded $\mathrm{TiO}_{2}$. On the other hand, 


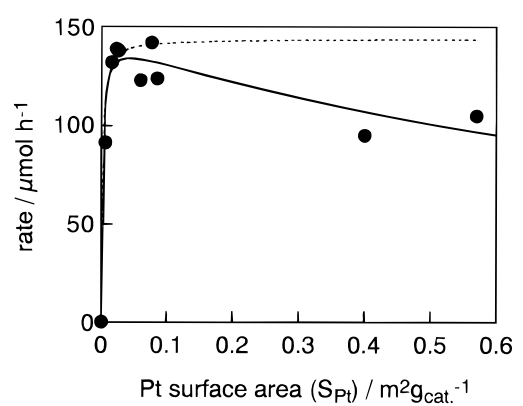

Figure 7. Rate of photocatalytic $\mathrm{H}_{2}$ evolution from aqueous 2-propanol solution as a function of Pt surface area $\left(S_{\mathrm{Pt}}\right)$.

the middle wavenumber peak $\left(2132 \mathrm{~cm}^{-1}\right)$ appeared only for the highly dispersed $\mathrm{Pt}-\mathrm{TiO}_{2}$ samples. Because this peak has been assigned to $\mathrm{CO}$ adsorbed on oxygen-covered $\mathrm{Pt}^{55}$ the partial oxidation of the Pt surface was also recognized.

Since it is rather difficult to imagine that platinum species on these catalysts were reduced only partly during the $\mathrm{H}_{2}$ reduction treatment at $753 \mathrm{~K}$, the formation of such oxidized species is attributed to gradual oxidation of the once formed $\mathrm{Pt}^{0}$ surface during storage under ambient conditions. The larger the surface area of $\mathrm{Pt}$, the faster it should be oxidized. Therefore, we regarded the presence of oxidized species as a result of high dispersion of $\mathrm{Pt}$ on the $\mathrm{TiO}_{2}$ surface.

During the photocatalytic reaction, the species may be reduced to $\mathrm{Pt}^{0}$. That even $\mathrm{PtO}_{2}$ has been reduced to the metallic $\mathrm{Pt}^{0}$ sate in the photoirradiated alcoholic suspension ${ }^{48}$ supports this assumption. This leads to the idea that the more the Pt surface is oxidized, the more fresh $\mathrm{Pt}$ surface is exposed during photocatalytic reaction, and therefore, the actual surface of $\mathrm{Pt}$ may be larger than that measured by $\mathrm{H}_{2}$ absorption.

Photocatalytic Activity of $\mathrm{TiO}_{2}-\mathrm{Pt}$ for 2-Propanol Reaction. Photoirradiation onto the suspension of $\mathrm{TiO}_{2}-\mathrm{Pt}$ in aqueous 2-propanol under $\mathrm{Ar}$ atmosphere leads to the equimolar production of acetone and $\mathrm{H}_{2}$, as reported previously. ${ }^{23}$ The stoichiometry, as follows

$$
\mathrm{CH}_{3} \mathrm{CH}(\mathrm{OH}) \mathrm{CH}_{3}=\mathrm{CH}_{3} \mathrm{COCH}_{3}+\mathrm{H}_{2}
$$

was also confirmed to be within experimental error for the catalysts used in this study. Negligible byproducts other than acetone and $\mathrm{H}_{2}$ were detected. Under this circumstance, we could evaluate the overall rate of reaction 3 by measuring the rate of $\mathrm{H}_{2}$ production. For all the catalysts, almost linear production of $\mathrm{H}_{2}$ was observed in the time-course curve unless the consumption of 2-propanol was so marked. Consequently, we determined the rate of photocatalytic dehydrogenation (reaction 3) from the initial slope of $\mathrm{H}_{2}$ evolution and plotted it in Figure 7 as a function of Pt surface area evaluated from volumetric gas adsorption measurements. Apparently no reaction proceeded in the absence of loaded Pt. The maximum rate was obtained with a Pt surface area of $0.02-0.05 \mathrm{~m}^{2} \mathrm{~g}_{\mathrm{cat}}{ }^{-1}$, corresponding to 0.2 and $0.5 \mathrm{wt} \% \mathrm{Pt}$-loaded $\mathrm{TiO}_{2}$. With the further increase in Pt surface area, i.e., amount of loaded Pt, the rate was constant or rather reduced. A similar dependence of the photocatalytic reaction rate on the amount of loaded $\mathrm{Pt}$ was reported previously. ${ }^{27,56-59}$

All the catalysts in the series were well suspended in aqueous solution under vigorous magnetic stirring, and the photon flux incident upon the suspensions can be considered to be constant, regardless of the amount of loaded Pt. The above-mentioned dependence is, therefore, attributed only to an effect of Pt on a mechanism that includes $\mathrm{h}^{+}$and $\mathrm{e}^{-}$generated by photoabsorption of $\mathrm{TiO}_{2}$. A noticeable fact is that the maximum (or
SCHEME 1

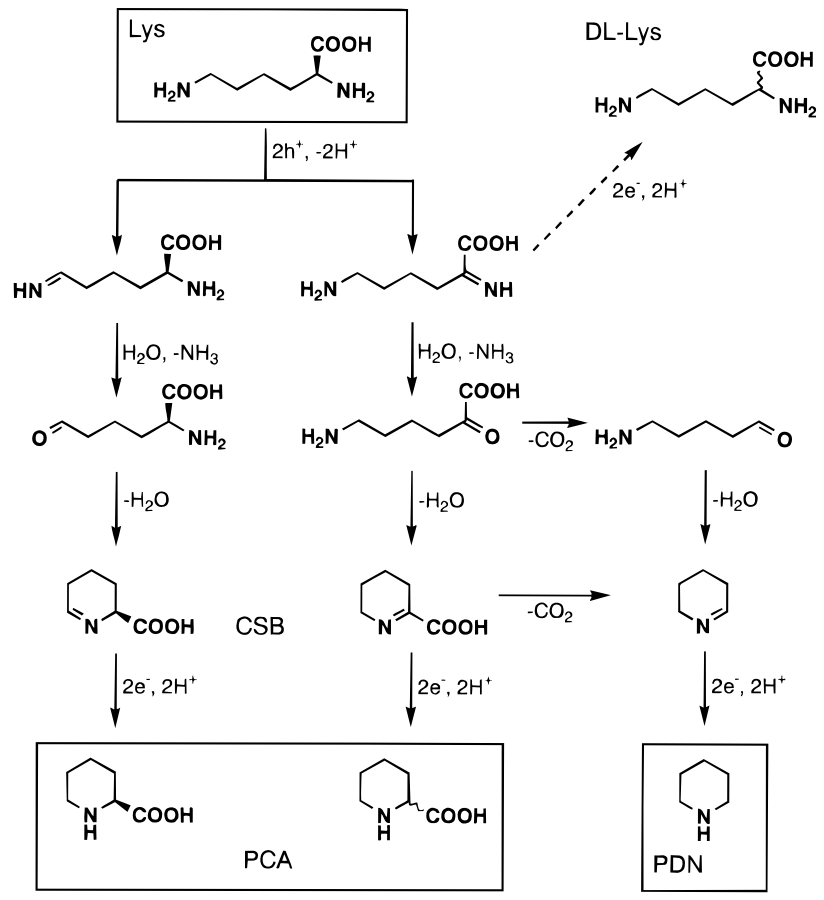

saturated) rate was obtained at the $0.2-0.5 \mathrm{wt} \%$ region, and this will be discussed in the next section.

Photocatalytic Activity of $\mathrm{TiO}_{2}-\mathrm{Pt}$ for Conversion of Lys. In this photocatalytic reaction system, along with the consumption of Lys, $(S, R)$-pipecolinic acid $((S, R)$-PCA) and ammonia $\left(\mathrm{NH}_{3}\right)$ were produced as main products as well as piperidine (PDN), $\mathrm{H}_{2}$, and carbon dioxide $\left(\mathrm{CO}_{2}\right)$ as byproducts. Analyses of material balances suggested that unidentified product(s) should be formed and may be an $\alpha$-carboxy Schiff base intermediate (CSB) and/or its hydrolyzed form ( $\alpha$-keto acid or $\delta$-aldehyde; see Scheme 1)..$^{50}$ The nominal stoichiometries producing PCA, PDN, and $\mathrm{H}_{2}$ are as follows:

$$
\begin{aligned}
& \mathrm{H}_{2} \mathrm{~N}\left(\mathrm{CH}_{2}\right)_{4} \mathrm{CH}\left(\mathrm{NH}_{2}\right) \mathrm{COOH}=\mathrm{HN}\left(\mathrm{CH}_{2}\right)_{4} \mathrm{CHCOOH}+\mathrm{NH}_{3} \\
& \text { (main) (4) } \\
& \mathrm{H}_{2} \mathrm{~N}\left(\mathrm{CH}_{2}\right)_{4} \mathrm{CH}\left(\mathrm{NH}_{2}\right) \mathrm{COOH}=\underset{ }{\stackrel{\mathrm{HN}}{\mathrm{N}\left(\mathrm{CH}_{2}\right)_{4}+\mathrm{CH}_{2}}+} \mathrm{CO}_{2} \text { (minor) }
\end{aligned}
$$

$\mathrm{H}_{2} \mathrm{~N}\left(\mathrm{CH}_{2}\right)_{4} \mathrm{CH}\left(\mathrm{NH}_{2}\right) \mathrm{COOH}=$ oxidized intermedate +

$$
\mathrm{NH}_{3}+\mathrm{H}_{2} \text { (minor) }
$$

where oxidized intermediate represents the unidentified product(s). The balance of product yields, except for $\mathrm{H}_{2}$, was almost consistent with these stoichiometries.

The proposed reaction process of photocatalytic formation of optically active and/or racemic PCA from Lys was shown in Scheme 1. ${ }^{29,30}$ It has been proved that either the $\alpha$ - or $\epsilon$-amino group in Lys is oxidized by $\mathrm{h}^{+}$to the corresponding imines, which are then hydrolyzed into $\alpha$-keto acid or $\delta$-aldehyde, respectively. Intramolecular condensation of the carbonyl group with the residual amino group provides cyclic Schiff base (CSB) intermediates to undergo reduction by $\mathrm{e}^{-}$into PCA. Although cadmium sulfide (CdS)-based photocatalysts favor the $\alpha$-keto acid pathway giving racemic PCA from optically active lysine, $\mathrm{TiO}_{2}$-based catalyst predominantly $(50-60 \%$ enantio excess of $(S)$-isomer (\%ee- $(S))$ ) produces $(S)$-PCA via the $\delta$-aldehyde pathway. ${ }^{29}$ The reason for such different reaction 


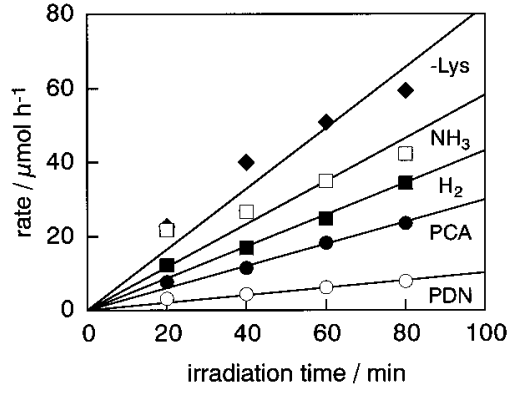

Figure 8. Time dependence of Lys consumption and production of PCA, PDN, $\mathrm{H}_{2}$, and $\mathrm{NH}_{3}$ in the photocatalytic reaction of $20 \mathrm{mmol}$ $\mathrm{dm}^{-3}$ aqueous Lys solution with $0.2 \mathrm{wt} \%$ Pt-loaded $\mathrm{TiO}_{2}$.

pathways has been partly clarified to be accounted for by the difference in oxidation ability between $\mathrm{CdS}$ and $\mathrm{TiO}_{2} ;{ }^{60} \mathrm{CdS}$, having a shallower valence band position, ${ }^{1}$ i.e., lesser oxidation ability, can oxidize the deprotonated form of the amino group but not the protonated (ammonium form of) one. Judging from the $\mathrm{p} K_{\mathrm{a}}$ of the two kinds of amino group of Lys, the $\alpha$-amino moiety is depronated while the $\epsilon$-one is protonated under the photocatalytic reaction conditions employed in our studies. Thereby, the CdS-induced photocatalytic reaction proceeds only via the $\alpha$-keto acid pathway. On the other hand, $\mathrm{TiO}_{2}$ with a relatively high oxidation potential may oxidize both amino groups in Lys to form $(S)$-excess product. Under these circumstances, the stereoselectivity of product PCA, i.e., \%ee$(S)$, should depend only on the oxidation ability of photocatalyst; neither recognition nor stereo control works in the reduction step with $\mathrm{e}^{-}$. Actually the \%ee- $(S)$ was almost constant (ca. $60 \%$ ) for all the present $\mathrm{TiO}_{2}-\mathrm{Pt}$ photocatalysts with different Pt loadings, indicating both the Pt deposits affected the reduction predominantly and that the oxidation ability of $\mathrm{TiO}_{2}$ was not modified by $\mathrm{Pt}$ loading.

Scheme 1 also shows a presumed mechanism of PDN formation, which has been one of the characteristics for the $\mathrm{TiO}_{2}$-based photocatalyst. An $\omega$-amino aldehyde intermediate may be formed via decarboxylation of the $\alpha$-keto acid and/or $\alpha$-imino intermediate and undergo intramolecular cyclization into a cyclic Schiff base. Decarboxylation of CSB may also produce the same intermediate, but we have not yet distinguished these pathways. Another possible reaction scheme producing PDN is decarboxylation of the final product PCA. However, a control experiment using PCA as a starting material showed that the rate of PDN formation was markedly slower than that observed in the present experiments. ${ }^{29,61}$ Furthermore, as shown in Figure 8, the time course of PDN production, as well as the other reaction products, was almost linear without appreciable induction period. If PCA is a precursor for PDN, an appreciable induction period is expected to appear. The latter mechanism via PCA could be excluded from these findings. Harada and co-workers reported the photocatalytic reaction of $\alpha$-hydroxycarboxylic acid, lactic acid, and showed the difference in the products between the systems including $\mathrm{TiO}_{2}$ and CdS. ${ }^{62,63}$ The $\mathrm{TiO}_{2}-\mathrm{Pt}$ mainly gives the decarboxylated and dehydrogenated product, acetaldehyde, while $\mathrm{CdS}$ gives the simple dehydrogenated product, pyruvic acid. The tendency of the $\mathrm{TiO}_{2}$ photocatalyst to favor the formation of decarboxylated product resembles the photocatalytic reaction of Lys. At any rate, PDN is produced via combination of oxidation with $\mathrm{h}^{+}$and reduction with $\mathrm{e}^{-}$, similar to PCA (Scheme 1).

From the linear time course of formation of all the detected products and consumption of Lys (see Experimental Section for Lys and $\mathrm{NH}_{3}$ ), the initial rate was evaluated and shown in Figure 9 as a function of the Pt surface area. The Lys consumption corresponds to the overall reaction, and PCA, PDN,

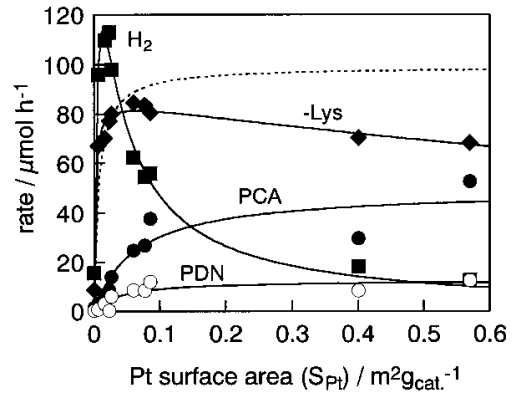

Figure 9. Rates of Lys consumption and production of PCA, PDN, and $\mathrm{H}_{2}$ as a function of $\mathrm{Pt}$ surface area $\left(S_{\mathrm{Pt}}\right)$.

\section{SCHEME 2}

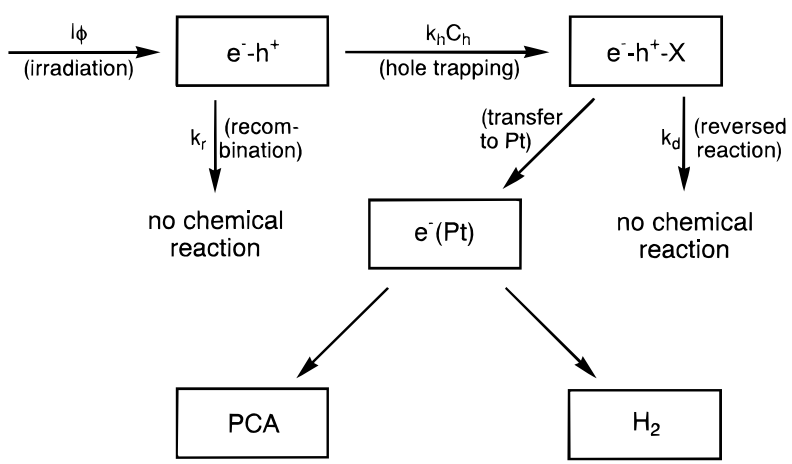

and $\mathrm{H}_{2}$ yields correspond to reactions 4-6, respectively. On the assumption that the overall reaction consists of reactions 4-6 only, the sum of these three products should be equal to Lys consumption but was much larger than expected. This could be interpreted by undetected reactions that produced excess $\mathrm{H}_{2}$, e.g., oxidation of $\mathrm{NH}_{3}$ or oxidized intermediate accompanying $\mathrm{H}_{2}$ evolution; $\mathrm{H}_{2}$ formation has been commonly observed for aqueous solutions of such organic materials. ${ }^{64} \mathrm{We}$ estimated, therefore, for convenience, the rate of reaction $6\left(\mathrm{H}_{2}\right.$ formation) by subtracting the sum of the yields of PCA and PDN from the Lys consumption, and the corrected rate of $\mathrm{H}_{2}$ formation was used hereafter.

The dependence of the overall rate on the Pt loading was quite similar to that in the 2-propanol solution; the rate increased drastically at lower (less than ca. $0.5 \mathrm{wt} \%$ ) loadings and became constant or a little decreased by the further higher loadings. Also, the yields of PCA and PDN increased with Pt loading, but their slope is rather smaller than that of the overall rate. On the other hand, the rate of $\mathrm{H}_{2}$ evolution showed its maximum at the lower Pt loading of $0.02 \mathrm{~m}^{2} \mathrm{~g}_{\text {cat }}{ }^{-1}$ and decreased in contrast to the PCA and PDN yields, suggesting a competitive use of $\mathrm{e}^{-}$on the Pt surface by $\mathrm{H}^{+}$(as a precursor of $\mathrm{H}_{2}$ ) and cyclic Schiff base intermediates (for PCA and PDN).

Simulation of Dependence on Pt Loadings in 2-Propanol System. In previous papers, ${ }^{35-38}$ we have shown that a simple kinetic model can interpret the behavior of photocatalytic reaction in aqueous $\mathrm{TiO}_{2}$ suspensions containing $\mathrm{Ag}^{+}$and/or 2-propanol. The model consists of recombination and trapping of an $\mathrm{e}^{-}-\mathrm{h}^{+}$pair $\left(\mathrm{e}^{-}-\mathrm{h}^{+}\right)$generated in the $\mathrm{TiO}_{2}$ particle by photoirradiation and was modified for the present photocatalytic reaction system containing Pt deposits, as shown in Scheme 2. In the previous reports, the trapping of $\mathrm{e}^{-}-\mathrm{h}^{+}$by both electron donor $\left(\mathrm{h}^{+}\right.$trapping) and electron acceptor ( $\mathrm{e}^{-}$trapping) was presumed and consistent with the results. However, in the absence of strong electron acceptors such as $\mathrm{Ag}^{+}$, the $\mathrm{e}^{-}$ trapping may be neglected, and the photocatalytic reactions shown here proceed via $\mathrm{h}^{+}$trapping by a surface-adsorbed reductant $(\mathrm{X}), 2$-propanol or Lys, to form a complex $\left(\mathrm{e}^{-}-\mathrm{h}^{+}-\right.$ 
$\mathrm{X})$. The complex is nominal, i.e., introduced for the interpretation of results, and its physical meaning is not discussed here. It was presumed that in the absence of Pt deposits the complex undergoes deactivation (with a rate constant $k_{\mathrm{d}}$ ), i.e., recombination of the pair to yield no appreciable chemical reaction, while the Pt deposits would promote separation of the complex into $\mathrm{e}^{-}$on the Pt surface and oxidized substrate on the $\mathrm{TiO}_{2}$ surface. This mechanism is consistent with the fact that bare $\mathrm{TiO}_{2}$ cannot produce appreciable amounts of products, $\mathrm{H}_{2}$ and acetone, from aqueous 2-propanol solution, while appreciable amounts of acetone are obtained in the presence of an electron donor $\mathrm{Ag}^{+}$, showing that $\mathrm{TiO}_{2}$ has enough ability to oxidize 2-propanol even without Pt deposits and that the negligible $\mathrm{H}_{2}$ yield is due to the lesser ability of the $\mathrm{TiO}_{2}$ surface to reduce $\mathrm{H}^{+}$with $\mathrm{e}^{-}$. In another representation, photoexcited electrons are accumulated in the $\mathrm{TiO}_{2}$ particles without $\mathrm{Pt}$ and they enhance the recombination of $\mathrm{e}^{-}-\mathrm{h}^{+}$. Dunn and co-workers have shown the evidence of $\mathrm{e}^{-}$accumulation by the slurry electrode method. ${ }^{65}$

Under these conditions, rate of formation of $\mathrm{e}^{-}-\mathrm{h}^{+}$is expressed to be zero by the steady-state approximation as follows:

$$
\mathrm{d}\left[\mathrm{e}^{-}-\mathrm{h}^{+}\right] / \mathrm{d} t=I \phi-k_{\mathrm{r}}\left[\mathrm{e}^{-}-\mathrm{h}^{+}\right]-k_{\mathrm{h}} C_{\mathrm{h}}\left[\mathrm{e}^{-}-\mathrm{h}^{+}\right]=0
$$

where $I$ is flux of incident photons, $C_{\mathrm{h}}$ is surface concentration of reductant, $\phi$ is the efficiency of $\mathrm{e}^{-}-\mathrm{h}^{+}$generation in photoabsorbing $\mathrm{TiO}_{2}$, and $k_{\mathrm{r}}$ and $k_{\mathrm{h}}$ are the rate constants for recombination and $\mathrm{h}^{+}$trapping by surface-adsorbed species, respectively. The steady-state concentration $\left[\mathrm{e}^{--} \mathrm{h}^{+}\right]$is obtained from eq 7 as follows:

$$
\left[\mathrm{e}^{-}-\mathrm{h}^{+}\right]=I \phi /\left(k_{\mathrm{r}}+k_{\mathrm{h}} C_{\mathrm{h}}\right)
$$

The rate of $\mathrm{H}_{2}$ formation corresponding to the overall rate of photocatalytic dehydrogenation of 2-propanol (reaction 3 ) is derived as

$$
R^{\mathrm{P}}\left(\mathrm{H}_{2}\right)=\delta k_{\mathrm{h}}^{\mathrm{P}} C_{{ }_{\mathrm{h}}}^{\mathrm{P}}\left[\mathrm{e}^{-}-\mathrm{h}^{+}\right]=\delta k^{\mathrm{P}}{ }_{\mathrm{h}} C^{\mathrm{P}}{ }_{\mathrm{h}}\left(I \phi /\left(k_{\mathrm{r}}^{\mathrm{P}}+k_{\mathrm{h}}^{\mathrm{P}} C^{\mathrm{P}}{ }_{\mathrm{h}}\right)\right)
$$

where $\delta$ is the probability of the trapped hole $\left(\mathrm{e}^{-}-\mathrm{h}^{+}-\mathrm{X}\right)$ to be utilized for chemical reaction, being in a range $0-1$. If $k_{\mathrm{h}}^{\mathrm{P}}$, $C^{\mathrm{P}}{ }_{\mathrm{h}}$, and $k^{\mathrm{P}}$ are independent of the degree of platinization, $R^{\mathrm{P}}\left(\mathrm{H}_{2}\right)$ should be proportional to $\delta$ and the ratio of charge separation of $\mathrm{e}^{-}-\mathrm{h}^{+}-\mathrm{X}$, and the curve in Figure 7 corresponds to the dependence of $\delta$ on the Pt surface area.

Here, we attributed the $\delta$ dependence to the proportion of $\mathrm{TiO}_{2}$ particles loaded with at least one $\mathrm{Pt}$ deposit $\left(\mathrm{P}_{\mathrm{Pt}}=1-\right.$ $P(0)$ ). Since the rate expression (eq 9) is the sum of the rates of the photocatalytic reaction that occurred on each $\mathrm{TiO}_{2}$ particle, $\delta$, as well as other constants, should be treated by considering the distribution of $\mathrm{TiO}_{2}$ particles of different physical properties. For example, $\delta$ might be zero for the $\mathrm{TiO}_{2}$ particle without $\mathrm{Pt}$ deposits, while it might be an appreciable value between zero and unity for Pt-loaded $\mathrm{TiO}_{2}$. As shown in Figure $3, P_{\mathrm{Pt}}$ is estimated to be nearly unity with Pt loadings of $>0.3$ wt $\%$ at which the rate of $\mathrm{H}_{2}$ evolution (Figure 7) was saturated. Since the precise evaluation of $P_{\mathrm{Pt}}$ from TEM observation might be difficult, the present interpretation remains a qualitative one. However, it seems rather reasonable to recognize from the results that only one $\mathrm{Pt}$ deposit can act as a reduction site in such a small $\mathrm{TiO}_{2}$ particle of a few dozen nanometers, i.e., $\mathrm{e}^{-}$ could move in the whole range of the $\mathrm{TiO}_{2}$ particle.

Another characteristic of $\delta$ dependence is the negative effect by high Pt loading, i.e., the increase in the number of Pt deposits per $\mathrm{TiO}_{2}$ particle may reduce the rate. Although we have no

\begin{tabular}{|c|c|c|c|}
\hline parameter & physical meaning & 2-propanol & Lys \\
\hline$a$ & $I \phi k_{\mathrm{h}} C_{\mathrm{h}} /\left(k_{\mathrm{r}}+k_{\mathrm{h}} C_{\mathrm{h}}\right)$ & 144 & 99 \\
\hline$b$ & $\begin{array}{l}\text { deactivation of trapped } \\
\text { pair }\left(\mathrm{e}^{-}-\mathrm{h}^{+}-\mathrm{X}\right)\end{array}$ & 0.0016 & 0.0070 \\
\hline$d$ & $\begin{array}{l}\text { negative effect by } \\
\text { excessive Pt loading }\end{array}$ & 0.87 & 0.85 \\
\hline
\end{tabular}

TABLE 2: Parameters for the $\mathrm{TiO}_{2}-\mathrm{Pt}$ Photocatalytic Reaction on 2-Propanol and Lys

experimental evidence, four possible reasons are presumed for such negative effect. First, we consider the effect of interference of incident light by the loaded Pt that causes the decrease in photon flux I. Similarly, the loaded Pt may interefere with the adsorption of the reductant 2-propanol on the $\mathrm{TiO}_{2}$ surface and modify the apparent surface concentration $C_{\mathrm{h}}$. The third possible reason is the increase in the probability of recombination of $\mathrm{e}^{--} \mathrm{h}^{+}$by loaded Pt. It is plausible that the Pt deposits act as a recombination center for the pairs. ${ }^{66,67}$ As for eq $9, k_{\mathrm{r}}$ should be increased by excessive Pt loading. The fourth reason is the increase in the re-reduction of the oxidized intermediate $\left(\mathrm{e}^{-}-\mathrm{h}^{+}-\mathrm{X}\right)$ at Pt. This closely resembles the recombination and can be inferred qualitatively by the increase of $k_{\mathrm{d}}$ along with the increase in Pt. However, other interpretations are possible.

As discussed above, the parameter determining the overall rate, $\delta$, might reflect the distribution of $\mathrm{Pt}$ deposits on $\mathrm{TiO}_{2}$ particles and may not be related directly to the Pt surface area $S_{\mathrm{Pt}}$. However, for convenience, we tried to reproduce the rate dependence as a function of $S_{\mathrm{P}}$ by assuming that the saturation of the rate and the negative effect are introduced by $S_{\mathrm{P} t} /(b+$ $\left.S_{\mathrm{Pt}}\right)$ and $1 /\left(1+d S_{\mathrm{Pt}}\right)$, respectively ( $b$ and $d$ are constants). Thus, an empirical formula is derived:

$$
R^{\mathrm{P}}\left(\mathrm{H}_{2}\right)=a^{\mathrm{P}} S_{\mathrm{Pt}} /\left(\left(b^{\mathrm{P}}+S_{\mathrm{Pt}}\right)\left(1+d^{\mathrm{P}} S_{\mathrm{Pt}}\right)\right)
$$

The procedure for the determination of three parameters, $a^{\mathrm{P}}$, $b^{\mathrm{P}}$, and $d^{\mathrm{P}}$, was as follows. Since we could neglect the negative effect of $S_{\mathrm{Pt}}$ in the lower $S_{\mathrm{Pt}}$ region, the data points of $S_{\mathrm{Pt}}<0.5$ $\mathrm{m}^{2} \mathrm{~g}_{\text {cat }}{ }^{-1}$ were fitted to eq $10\left(\right.$ with $\left.d^{\mathrm{P}}=0\right)$ by the least-squares method as a broken line in Figure 7. Comparison of eq 10 with and without $d^{\mathrm{P}}$ led to a linear equation of a ratio of apparent $\left(R^{\mathrm{P}}\left(\mathrm{H}_{2}\right)\right)$ and ideal $\left(R_{0}{ }^{\mathrm{P}}\left(\mathrm{H}_{2}\right)\right.$, shown in Figure 7$)$ rates as a function of $S_{\mathrm{Pt}}$ :

$$
R^{\mathrm{P}}\left(\mathrm{H}_{2}\right) / R_{0}{ }^{\mathrm{P}}\left(\mathrm{H}_{2}\right)=1+d^{\mathrm{P}} S_{\mathrm{Pt}}
$$

In practice, the corresponding plot was almost linear and gave $d^{\mathrm{P}}$ as 0.87 . This $d^{\mathrm{P}}$ was used for feedback calculation of $R_{0} \mathrm{P}\left(\mathrm{H}_{2}\right)$ from the observed values at lower $\mathrm{Pt}$ loading, and $R_{0}{ }^{\mathrm{P}}\left(\mathrm{H}_{2}\right)$ was fitted again to eq 10 , but almost the same saturation curve was obtained. The ideal saturation limit, $a^{\mathrm{P}}$, the constant relating to the deactivation of reductively trapped $\mathrm{e}^{-}-\mathrm{h}^{+}\left(\mathrm{e}^{-}-\right.$ $\left.\mathrm{h}^{+}-\mathrm{X}\right), b^{\mathrm{P}}$, and the coefficient for the negative effect of the $\mathrm{Pt}$ deposit, $d^{\mathrm{P}}$, have been obtained as listed in Table 2 . The simulated dependence of the overall rate is shown by a solid line in Figure 7.

Simulation of Dependence on Pt Loadings in Lys System. In the reaction of Lys, essentially the same equation is derived by using superscript L, by analogy with the above-mentioned 2-propanol system.

$$
R^{\mathrm{L}}(-\mathrm{Lys})=a^{\mathrm{L}} S_{\mathrm{Pt}} /\left(\left(b^{\mathrm{L}}+S_{\mathrm{Pt}}\right)\left(1+d^{\mathrm{L}} S_{\mathrm{Pt}}\right)\right)
$$

Fitting of the observed dependence (Figure 9) was operated in a similar manner as that for the 2-propanol system to obtain the parameters (Table 2) and the simulation curve (solid line in Figure 9). 
Comparison of the parameters with those for 2-propanol gave some information on the difference in the mechanism and reactivity of these substrates. First, concerning the coefficient of negative effect of excess Pt, an almost identical value $d=$ 0.85 (though its physical meaning of absolute value could not be discussed) was obtained in both systems. This allows us to imagine that the inhibitory effect by excess $\mathrm{Pt}$ is attributable to the change in the intrinsic properties of photocatalyst particles, e.g., the decrease in incident photons or accelerated recombination of $\mathrm{e}^{-}-\mathrm{h}^{+}$may account for that.

On the other hand, the parameter $a$, corresponding to $I \phi k_{\mathrm{h}} C_{\mathrm{h}} /$ $\left(k_{\mathrm{r}}+k_{\mathrm{h}} C_{\mathrm{h}}\right)$ in eq 9 , for the two reactions was a little different; $a^{\mathrm{P}}$ was ca. 1.5 times larger than $a^{\mathrm{L}}$. Since the photoirradiation conditions affecting $I$ and $\phi$ were constant and $k_{\mathrm{r}}$ should be common, the difference in $k_{\mathrm{h}} C_{\mathrm{h}}$ should account for it. The initial concentration of 2-propanol, $100 \mathrm{mmol} \mathrm{dm}^{-3}$, was 5 times greater than that of Lys $\left(20 \mathrm{mmol} \mathrm{dm}^{-3}\right)$, but under the present conditions the amount of both substrates adsorbed $\left(C_{\mathrm{h}}\right)$ on the catalyst surface might be in the saturated region of Langmuirian isotherm, ${ }^{38}$ and thereby, the difference in $C_{\mathrm{h}}$ should not be as pronounced between the two substrates. It seems that the ability of reductive trapping of $\mathrm{e}^{-}-\mathrm{h}^{+}$by the surface-adsorbed reductants $\left(k_{\mathrm{h}}\right)$ is of the same order.

In contrast to the above two parameters, parameter $b$ showed a remarkable difference between 2-propanol and Lys. This parameter should reflect the efficiency of charge separation of $\mathrm{e}^{-}-\mathrm{h}^{+}-\mathrm{X}$ and therefore depends on the property of $\mathrm{X}$. If the complex undergoes efficient deactivation with relatively larger $k_{\mathrm{d}}, b$ becomes larger to result in a decrease in the overall rate. Thus, $b$ shows the fate of oxidized intermediate $\mathrm{e}^{-}-\mathrm{h}^{+}-\mathrm{X}$ whether it gives chemical products or not. The observed value of Lys was more than 4 times greater than that for 2-propanol, indicating that the pair trapped by Lys tends to undergo deactivation to release unreacted Lys. Recently, we have reported that Lys, as well as the other typical amino acids, underwent racemization by photocatalytic reaction on $\mathrm{CdS}^{49}$ and $\mathrm{TiO}_{2}{ }^{50}$ particles. This racemization reaction involved oxidation of Lys to lose its optical activity followed by reduction to reproduce racemic Lys. Pt loading inhibited the racemization by acting as a reduction site with $\mathrm{e}^{-}$to result in a charge separation of $\mathrm{e}^{-}-\mathrm{h}^{+}$. At present we have no structural information on the intermediate for the Lys racemization and whether the intermediate is identical to that in this paper, $X$, or not. Actually, no appreciable amount of $(R)$-lysine, however, could be detected with the $\mathrm{TiO}_{2}-\mathrm{Pt}$ catalysts. This suggests that the intermediate $\mathrm{e}^{-}-\mathrm{h}^{+}-\mathrm{X}$ does not account for the racemization at least for the $\mathrm{TiO}_{2}$ system.

Dependence of Product Distribution in Lys System on Pt Loadings. As Figure 9 shows, the dependence of each product from Lys on $S_{\mathrm{Pt}}$ was markedly different from that of the overall reaction rate, indicating that $\mathrm{Pt}$ loadings influence the product distribution as well as the overall rate. This is reasonable because the products, PCA (PDN) and $\mathrm{H}_{2}$, should appear via reduction by $\mathrm{e}^{-}$, most likely on Pt deposits, of CSB and $\mathrm{H}^{+}$(or $\mathrm{H}_{2} \mathrm{O}$ ).

It is quite natural to imagine that oxidation by $\mathrm{h}^{+}$may occur on the whole $\mathrm{TiO}_{2}$ surface, not limited to the sites neighboring the $\mathrm{Pt}$ deposit(s) as discussed in the preceding section. Hence, for the intermediate species, such as CSB, it is necessary to move along the $\mathrm{TiO}_{2}$ surface to the deposited $\mathrm{Pt}$ to be reduced. This is in contrast to the 2-propanol system where the oxidation product, acetone, liberated by oxidation with $\mathrm{h}^{+}$, is then allowed to be desorbed from the surface, while protons may accept $\mathrm{e}^{-}$ on the Pt to liberate $\mathrm{H}_{2}$. Assuming that the intermediate(s) in the Lys system undergoes further decomposition, the final

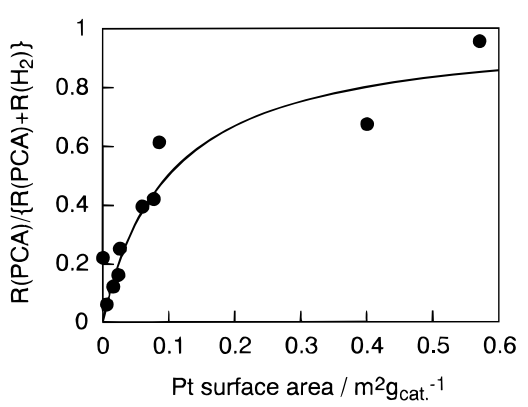

Figure 10. Selectivity of PCA production as a function of Pt surface area $\left(S_{\mathrm{Pt}}\right)$.

product, PCA, can be obtained only when the intermediate reaches the Pt site within its lifetime. Otherwise, $\mathrm{e}^{-}$should be consumed by the side reaction, $\mathrm{H}_{2}$ evolution. As for the intermediate, we could detect a small amount of CSB in the reaction mixture as a mixture of CSB, its ring-opened (hydrolyzed) keto acid form, and enamine form. ${ }^{50}$ The concentration might be low and changed during the photoirradiation; at least it should be zero at the commencement of photoirradiation but an appreciable amount was there in the reaction mixture. This leads to the time course of PCA production, which appears after some induction period due to the accumulation of the source, CSB. However, in practice, PCA was observed without appreciable delay and increased linearly with time, as shown in Figure 8. This suggests that an alternative fate of CSB, reduction to $\mathrm{PCA}$ or further (oxidative) decomposition, leaving a negligible amount of CSB scarcely detected by GC-MS. ${ }^{50}$ In other words, CSB once liberated and desorbed from the $\mathrm{TiO}_{2}$ surface is not reduced into the final product.

The selectivity of PCA (along with the similar redox product, $\left.\mathrm{PDN} ; R^{\mathrm{L}}(\mathrm{PCA}) /\left(R^{\mathrm{L}}(\mathrm{PCA})+R^{\mathrm{L}}\left(\mathrm{H}_{2}\right)\right)\right)$ is plotted as a function of $S_{\mathrm{Pt}}$ in Figure 10. On the basis of these considerations, the dependence of products from Lys is interpreted as follows. At low Pt loading, where the overall rate is increased with $S_{\mathrm{Pt}}, \mathrm{CSB}$ as well as the other intermediate undergoes predominantly further oxidation into unidentified product, and $\mathrm{H}_{2}$ is liberated as a main reduction product. With the increase in $S_{\mathrm{Pt}}$, the intermediate(s) tends to undergo reduction to $\mathrm{PCA}$ at the $\mathrm{Pt}$ deposits. The most efficient catalyst $(2 \mathrm{wt} \%)$ induced almost quantitative $(>95 \%)$ reduction of the oxidation product from Lys.

Thus, the importance of control of distance between the surface sites for oxidation and reduction is expected. In relation to this, it is possible to evaluate the distance of $\mathrm{Pt}$ deposits by assuming that the deposits are dispersed uniformly on the $\mathrm{TiO}_{2}$ surface and located at the center of a shared circle with radius, $r\left(\mathrm{Pt} / \mathrm{TiO}_{2}\right)$ (average distance between two Pt deposits twice as large as $\left.r\left(\mathrm{Pt} / \mathrm{TiO}_{2}\right)\right)$. This estimation should be valid only for the Pt loading, which gives at least two Pt deposits on each $\mathrm{TiO}_{2}$ particle; the calculation was limited to $\mathrm{Pt}$ loading $>1 \mathrm{wt}$ $\%$. Figure 11 shows the selectivity as a function of $r\left(\mathrm{Pt} / \mathrm{TiO}_{2}\right)$. Obviously, the selectivity was improved with reducing $r(\mathrm{Pt} /$ $\mathrm{TiO}_{2}$ ). Extrapolation of the line suggests that stoichiometric production of PCA (with PDN), without $\mathrm{H}_{2}$ liberation, may be achieved at $r\left(\mathrm{Pt} / \mathrm{TiO}_{2}\right)$ of ca. $5 \mathrm{~nm}$. This tells us that the $\mathrm{Pt}$ deposit can reduce all the intermediate species produced on the $\mathrm{TiO}_{2}$ surface sites located within $5 \mathrm{~nm}$. Thus, for the selective production of PCA from Lys, but not for the faster Lys consumption, highly dispersed Pt deposits are required, although the overal rate is a little reduced by the excessively higher Pt loading. We have found a similar dependence of PCA selectivity on $S_{\mathrm{Pt}}$ for different Pt-loaded $\mathrm{TiO}_{2}$ powders, and this will be reported elsewhere. 


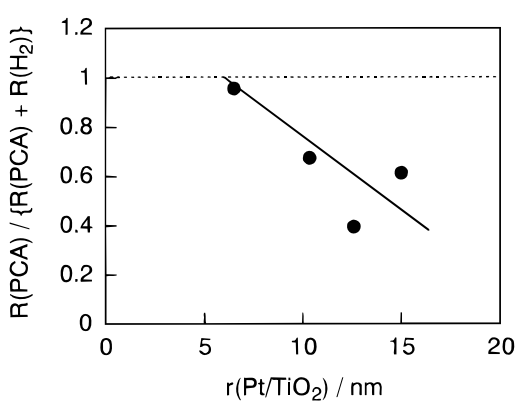

Figure 11. Selectivity of PCA production as a function of $r\left(\mathrm{Pt} / \mathrm{TiO}_{2}\right)$.

Several procedures have been reported for the platinization of $\mathrm{TiO}_{2}$, e.g., impregnation followed by reduction, ${ }^{17,27}$ photodeposition, ${ }^{15,16}$ mechanical mixing with platinum black ${ }^{23,64}$ or precipitation from platinum sol, ${ }^{68}$ but few reports compared the efficiency of platinization onto $\mathrm{TiO}_{2}$ particles. Mills has described in a communication that among these platinization techniques the sol precipitation and photodeposition methods gave the efficient $\mathrm{TiO}_{2}-\mathrm{Pt}$ catalyst for photocatalytic $\mathrm{H}_{2}$ evolution from aqueous EDTA solution. ${ }^{68}$ For several $\mathrm{TiO}_{2}$ powders sol precipitation afforded photocatalytic activity, which was comparable to photodeposition. On the basis of the results in present studies, these previous results may be interpreted reasonably in terms of the distribution of Pt deposits on the $\mathrm{TiO}_{2}$ particles, not of the total number of loadings. Comparison of photocatalytic activity of $\mathrm{TiO}_{2}$ platinized via several procedures is now being investigated along this line.

\section{Conclusion}

The dependence of the rate on the amount of $\mathrm{Pt}$ was semiquantitatively simulated with a kinetic model by using the surface area of $\mathrm{Pt}$ as a parameter representing the physical property of Pt deposits. The selectivity of PCA from Lys strongly depended on the $\mathrm{Pt}$ amount, while the rate of $\mathrm{H}_{2}$ evolution from 2-propanol was rather insensitive. From the distribution of $\mathrm{Pt}$ deposits on $\mathrm{TiO}_{2}$ particles, it has been presumed that only one Pt deposit on a small (a few dozen nanometers in size) $\mathrm{TiO}_{2}$ particle is required for $\mathrm{H}_{2}$ evolution, but a larger amount of $\mathrm{Pt}$ is necessary for the adsorption and reduction of the intermediate CSB by photoexcited electrons. For the Lys system, it was presumed from the data analysis that the deposited $\mathrm{Pt}$ can reduce the intermediate produced at the $\mathrm{TiO}_{2}$ surface sites located within ca. $5 \mathrm{~nm}$. In both cases of 2-propanol and Lys, excess loading of Pt that reduced the overall rate may be due to the decrease in light absorption by $\mathrm{TiO}_{2}$ or enhanced recombination of electron-hole pairs. Thus, we have shown the role of $\mathrm{Pt}$ deposited on $\mathrm{TiO}_{2}$ in the photocatalytic reaction system under deaerated conditions and the optimum amount of loading for two different kinds of reactions. These results should be useful and applicable to the preparation of a wide range of noble-metal-loaded semiconductor photocatalysts for different kinds of reactions.

Acknowledgment. Financial support by the Kawakami Memorial Foundation and Kansai Research Foundation for Technology Promotion is gratefully acknowledged. This investigation was partly supported by the Grant-in-Aid on PriorityArea-Research on "Photoreaction Dynamics" from the Ministry of Education, Science, Sports, and Culture of Japan (No. 07228233). Part of this study was achieved under the support of the Joint Research Program of Catalysis Research Center, Hokkaido University. The authors are indebted to Professor Masashi Inoue and Dr. Kenji Wada (Kyoto University) for their technical advice on the TEM and XPS measurements, respec- tively, and also to Mr. Masahiro Naito (Kyoto University) for his skillful work in the preparation of an electric furnace for $\mathrm{H}_{2}$ reduction and photoirradiation apparatuses. Professor Akiko Aramata (Hokkaido University) is acknowledged for permission to use the FT-IR spectrometer.

\section{References and Notes}

(1) Kamat, P. V. Chem. Rev. 1993, 93, 267.

(2) Hagfeldt, A.; Grätzel, M. Chem. Rev. 1995, 95, 49.

(3) Bard, A. J. Science 1980, 207, 139.

(4) Sato, S.; White, J. M. Chem. Phys. Lett. 1981, 72, 83.

(5) Kawai, T.; Sakata, T. Chem. Phys. Lett. 1980, 72, 87.

(6) Duonghong, D.; Borgarello, E.; Grätzel, M. J. Am. Chem. Soc. 1981, 103,4685 .

(7) Borgarello, E.; Kiwi, J.; Pelizzetti, E.; Visca, M.; Grätzel, M. J. Am. Chem. Soc. 1981, 103, 6324.

(8) Sato, S.; White, J. M. J. Phys. Chem. 1981, 85, 592. 1237.

(9) Yamaguti, K.; Sato, S. J. Chem. Soc., Faraday Trans. 1985, 81,

(10) Sayama, K.; Arakawa, H. J. Chem. Soc., Chem. Commun. 1992, 150 .

(11) Sayama, K.; Arakawa, H. Chem. Lett. 1992, 253.

(12) Sayama, K.; Arakawa, H. J. Phys. Chem. 1993, 97, 531.

(13) Nakabayashi, S.; Fujishima, A.; Honda, K. Chem. Phys. Lett. 1983, 102,464 .

(14) Baba, R.; Nakabayashi, S.; Fujishima, A.; Honda, K. J. Phys. Chem. 1985, 89, 1902

(15) Kraeutler, B.; Bard, A. J. J. Am. Chem. Soc. 1978, 100, 4317.

(16) Kraeutler, B.; Bard, A. J. J. Am. Chem. Soc. 1978, 100, 5985.

(17) Pichat, P.; Herrmann, J.-M.; Disdier, J.; Courbon, H.; Mozzanega, M.-N. Nouv. J. Chim. 1981, 5, 627.

(18) Sakata, T.; Kawai, T. Chem. Phys. Lett. 1981, 80, 341.

(19) Domen, K.; Naito, S.; Onishi, T.; Tamaru, K. Chem. Lett. 1982 555 .

(20) Teratani, S.; Nakamichi, J.; Taya, K.; Tanaka, K. Bull. Chem. Soc. Jpn. 1982, 55, 1688.

(21) Harada, H.; Ueda, T. Nouv. J. Chim. 1984, 8, 123.

(22) Hussein, F. H.; Rudham, R. J. Chem. Soc., Faraday Trans. 1 1984, $80,2187$.

(23) Ohtani, B.; Nishimoto, S.-i.; Kagiya, T. J. Chem. Soc., Faraday Trans. 1 1985, 81, 2467.

(24) Nishimoto, S.-i.; Ohtani, B.; Shirai, H.; Kagiya, T. J. Polym. Sci., Polym. Lett. Ed. 1985, 23, 141.

(25) Fox, M. A.; Ogawa, H.; Pichat, P. J. Org. Chem. 1989, 54, 3847.

(26) Fox, M. A.; Dulay, M. T. Chem. Rev. 1993, 93, 341.

(27) Pichat, P.; Mozzanega, M.-N.; Disdier, J.; Herrmann, J.-M. Nouv. J. Chim. 1982, 6, 559.

(28) Ohtani, B. In Trends in Photochemistry and Photobiology; Council of Scientific Information, Research Trends: Trivandrum, India, 1994; Vol. 3 , p 531 .

(29) Ohtani, B.; Tsuru, S.; Nishimoto, S.-i.; Kagiya, T.; Izawa, K. J. Org. Chem. 1990, 55, 5551.

(30) Ohtani, B.; Aoki, E.; Iwai, K.; Nishimoto, S.-i. J. Photosci. 1994, 1,31

(31) Ohtani, B.; Iwai, K.; Kominami, H.; Matsuura, T.; Kera, Y.; Nishimoto, S.-i. Chem. Phys. Lett. 1995, 242, 315.

(32) Nishimoto, S.-i.; Ohtani, B.; Yoshikawa, T.; Kagiya, T. J. Am. Chem. Soc. 1983, 105, 7180.

(33) Ohtani, B.; Osaki, H.; Nishimoto, S.-i.; Kagiya, T. J. Am. Chem. Soc. 1986, 108, 308.

(34) Ohtani, B.; Osaki, H.; Nishimoto, S.-i.; Kagiya, T. Tetrahedron Lett. 1986, 27, 2019.

(35) Nishimoto, S.-i.; Ohtani, B.; Kajiwara, H.; Kagiya, T. J. Chem Soc., Faraday Trans. 1 1983, 79, 2685.

(36) Ohtani, B.; Okugawa, Y.; Nishimoto, S.-i.; Kagiya, T. J. Phys. Chem. 1987, 91, 3550.

(37) Ohtani, B.; Kakimoto, M.; Nishimoto, S.-i.; Kagiya, T. J. Phys Chem. 1988, 92, 5773.

(38) Ohtani, B.; Nishimoto, S.-i. J. Phys. Chem. 1993, 97, 920.

(39) Sato, S.; White, J. M. Chem. Phys. Lett. 1980, 72, 83.

(40) Kominami, H.; Matsuura, T.; Iwai, K.; Ohtani, B.; Nishimoto, S.i.; Kera, Y. Chem. Lett. 1995, 693.

(41) Moss, R. L. In Experimental Methods in Catalytic Research; Anderson, R. B., Dawson, P. T., Ed.; Academic Press: New York, 1976; Vol. 2, p 43.

(42) Satterfield, C. N. Heterogeneous Catalysis in Practice; McGrawHill: New York, 1980; p 82.

(43) Kunimori, K.; Uchijima, T.; Yamada, M.; Matsumoto, H.; Hattori, T.; Murakami, Y. Appl. Catal. 1982, 4, 67.

(44) Vannice, M. A.; Twu, C. C.; Moon, S. H. J. Catal. 1983, 79, 70.

(45) Anderson, J. F.; Burch, R. Appl. Catal. 1986, 25, 173.

(46) Sato, S.; Kunimatsu, K. J. Phys. Chem. 1984, 88, 175. 
(47) Nishimoto, S.-i.; Ohtani, B.; Kajiwara, H.; Kagiya, T. J. Chem. Soc., Faraday Trans. 1 1985, 81, 61.

(48) Ohtani, B.; Kakimoto, M.; Nishimoto, S.-i.; Kagiya, T. J. Photochem. Photobiol., A 1993, 70, 265.

(49) Ohtani, B.; Kawaguchi, J.-i.; Kozawa, M.; Nishimoto, S.-i.; Inui, T.; Izawa, K. J. Chem. Soc., Faraday Trans. 1995, 91, 1103.

(50) Ohtani, B.; Kawaguchi, J.-i.; Kozawa, M.; Nakaoka, Y.; Nosaka, Y.; Nishimoto, S.-i. J. Photochem. Photobiol., A 1995, 90, 75.

(51) Ohtani, B.; Goto, Y.; Nishimoto, S.-i.; Inui, T. J. Chem. Soc., Faraday Trans. 1996, 92, 4291.

(52) Feller, W. An Introduction to Probability Theory and Its Applications, 3rd ed.; John Wiley and Sons, Inc.: New York, 1950; Vol. 1, p 163. (53) Kim, K. S.; Winograd, N.; Dais, R. E. J. Am. Chem. Soc. 1971, $93,6296$.

(54) Hadjiivanov, K.; Saint-Just, J.; Che, M.; Tatibouet, J.-M.; Lamotte, J.; Lavalley, J.-C. J. Chem. Soc., Faraday Trans. 1994, 90, 2277.

(55) Tanaka, K.; White, J. M. J. Catal. 1983, 79, 81

(56) Mills, A.; Porter, G. J. Chem. Soc., Faraday Trans. 1 1982, 78, 3659 .
50 .

(57) Sakata, T.; Kawai, T.; Hashimoto, K. Chem. Phys. Lett. 1982, 88,

(58) Kiwi, J.; Grätzel, M. J. Phys. Chem. 1984, 88, 1302.

(59) Sakata, T.; Hashimoto, K.; Kawai, T. J. Phys. Chem. 1984, 88 , 5214.

(60) Ohtani, B.; Yako, T.; Samukawa, Y.; Nishimoto, S.-i.; Kanamura, K. Chem. Lett., in press.

(61) Ohtani, B.; Tsuru, S.; Kawaguchi, J.-i.; Nishimoto, S.-i. J. Org. Chem., to be submitted.

(62) Harada, H.; Sakata, T.; Ueda, T. J. Am. Chem. Soc. 1985, 107, 1773.

(63) Harada, H.; Ueda, T.; Sakata, T. J. Phys. Chem. 1989, 93, 1542.

(64) Kawai, T.; Sakata, T. Chem. Lett. 1981, 81.

(65) Dunn, W. W.; Aikawa, Y.; Bard, A. J. J. Am. Chem. Soc. 1981 103,3456

(66) Kobayashi, T.; Yoneyama, H. Private communication.

(67) Landsberg, P. T. Recombination in Semiconductors; Cambridge University Press: Cambridge, 1991; p 208.

(68) Mills, A. J. Chem. Soc., Chem. Commun. 1982, 367. 